\title{
Um lugar para a fotografia: uma breve análise da constituição e produção do Coletivo FotoBahia (1979-1980)*
}

A place for Photography: a brief analysis of constitution and production of FotoBahia Collective (1979-1980)

Elson De Assis Rabelo

Universidade Federal do Vale de São Francisco

Rafaela Novaes Feitoza

Universidade Federal do Vale de São Francisco

\section{Resumo}

Este trabalho analisa o surgimento e a produção do Coletivo FotoBahia, em Salvador, no final dos anos 1970, com o objetivo de colocar em discussão os propósitos de suas atividades, a elaboração da linguagem fotográfica e sua inserção na produção cultural baiana. Tomamos como documentos de trabalho as imagens dos catálogos de 1979 e 1980, o jornal FotoBahia de 1981 e os textos que Ihes acompanham, situando-os naquele momento. Ambos, fotos e textos, permitiram perceber o engajamento criativo daqueles fotógrafos e a tentativa de abertura para uma produção diversificada e abrangente que escavasse um novo lugar para suas imagens e seu reconhecimento.

Palavras-chave: Fotografia baiana, FotoBahia, Artes Visuais, Fotojornalismo.

\begin{abstract}
This work analyzes the appearing and the production of FotoBahia Collective, in Salvador, in the late 1970's, with the objective of fostering discussion about the purposes of its activities, the elaboration of the photographic language and its insertion in the cultural production of the Brazilian State of Bahia. We take as work documents images from the 1979 and 1980 catalogues. Both photos and texts allowed us to perceive the creative engagement of those photographers and the attempt of overture for a diversified and comprehensive production that could dig a new place for the images and their acknowledgement.
\end{abstract}

Keywords: Photography of Bahia, FotoBahia, Visual Arts, Photojournalism.

\footnotetext{
* Este artigo é resultado de pesquisa no âmbito do Projeto de Iniciação Científica intitulado "Espaços discursivos da imagem fotográfica na publicação FotoBahia", que tem apoio da FAPESB, vigência 2015-2016, e é desenvolvido no Laboratório de Cultura Visual e Cidades da Universidade Federal do Vale do São Francisco.
}

Revista Digital do LAV - Santa Maria - vol. 9, n. 1, p. 128 - 144. - jan./abr. 2016 ISSN 1983 - 7348 http://dx.doi.org/10.5902/1983734821927 
Como todos os demais meios de expressão, a fotografia, se há de ser totalmente honrada e direta, teria que estar relacionada com a vida contemporânea, com o pulsar do de hoje em dia (ABBOTT, 2003 [tradução nossa]).

\section{Introdução}

Ser fotógrafo não é ser somente a pessoa que aperta o botão da câmera e deixa ela fazer o resto do trabalho, ao contrário, há todo um desenvolvimento anterior a isso: a escolha do que seria registrado, o ângulo, o espaço, as pessoas, o momento, a luz e a sombra, o foco. Antes de clicar no botão, o fotógrafo interpreta aquele momento, aquilo que vê ou até mesmo aquilo que sente, e após essa reflexão e interpretação vem o click, seguido de um trabalho laboratorial, isto é, do tratamento das fotografias especialmente no caso da fotografia analógica -, das cópias, da exposição. As escolhas feitas pelo profissional determinam a obra final, ou seja, tudo aquilo que foi idealizado, trabalhado na cabeça do fotógrafo e depois registrado, conta como processo criativo; os pensamentos e desejos contam como caminhos que foram necessários para chegar à imagem final.

Isto posto, trataremos neste artigo sobre um período da fotografia no Estado da Bahia a partir de dois catálogos, de 1979 e 1980, produzidos pelo coletivo nomeado de Grupo de Fotógrafos da Bahia, também conhecido como FotoBahia. Discutiremos a criação do coletivo para a produção dessas fotografias, como e onde eram publicadas, quais os critérios de escolha das fotografias, e alguns dos temas e técnicas utilizadas. Para realizar essa análise, foram utilizadas as próprias imagens dos catálogos de 1979 e 1980, bem como seus textos introdutórios, além de bibliografia específica acerca da fotografia. Além disso, abordaremos a elaboração dos códigos fotográficos produzidos pelo coletivo enquanto linguagem para além da história das artes manuais tradicionais, isto é, discutiremos a dimensão semiótica da fotografia e suas possibilidades técnicas (KRAUSS, 2010). As fotografias em si, dos dois catálogos, serão tomadas em suas formas e temas, considerando o lugar escavado por essa fotografia deslocada dos grandes centros.

\section{O Coletivo FotoBahia e sua constituição}

O grupo FotoBahia surgiu em Salvador, em 1978 e durou até pelo menos 1984, com

Revista Digital do LAV - Santa Maria - vol. 9, n. 1, p. 128 - 144. - jan./abr. 2016 ISSN 1983 - 7348 http://dx.doi.org/10.5902/1983734821927 
uma iniciativa do fotógrafo mineiro Aristides Alves, para que os fotógrafos do Estado pudessem conhecer os trabalhos uns dos outros, interagir, trocar conhecimentos acerca da fotografia, tendo agregado nomes hoje importantes da fotografia baiana, como Adenor Gondim, Mário Cravo Neto, Euvaldo Macedo Filho, Célia Aguiar, Isabel Gouveia, Rino Marconi, Maria Sampaio, dentre muitos outros. Com a criação do coletivo FotoBahia, e foram realizadas exposições do grupo no período de 1978 a 1984, às vezes com patrocínio da Fundação Cultural do Estado e apoio da FUNART. Além de expor, o coletivo promoveu, também, seminários (como o Seminário "Perspectiva Profissional e Cultura do Fotógrafo na Bahia") e oficinas para os fotógrafos já atuantes e para as pessoas que se interessavam em conhecer mais a fundo a fotografia. Também entre as atividades do grupo, havia atividades de estudo e pesquisa sobre a fotografia.

Maria Beatriz Coelho, no livro Imagens da Nação, relata como se desenvolveu a fotografia no Brasil, a evolução das câmeras fotográficas, como funcionavam, quais as possibilidades dadas pelos equipamentos em diferentes épocas. Enfim, para compreender a história da fotografia é preciso passar também pela sua evolução histórica e técnica, questionar o porquê de essa ferramenta ter chamado a atenção dos artistas e conquistado o público. Ao longo do século $X X$, as câmeras deixaram de ser enormes e pesadas e tornaram-se máquinas que cabem na palma da mão, da mesma forma que as chapas evoluíram para os rolos de filmes, que as novas lentes passaram a ter melhor definição da imagem, permitindo realizar fotos num curto espaço de tempo, os instantâneos (COELHO, 2012, p. 21-31). Em nível internacional, isso foi largamente experimentado pela geração do fotojornalismo internacional, desde os anos 1930, o que foi responsável pela expansão do público. No Brasil, não foi diferente no Brasil, com o surgimento das revistas ilustradas de circulação nacional, como O Cruzeiro, Realidade e Manchete e, posteriormente com a segmentação do mercado.

No caso do coletivo FotoBahia, essa preocupação com a técnica tinha a ver com a própria origem de parte dos integrantes no fotojornalismo, o que os mobilizou para mudar a realidade difícil de fotógrafos sem formação e manejo tecnológico. Era preciso formar profissionais que soubessem não só utilizar o flash, o zoom, enquadrar, focar, mas que soubesse também tratar essas imagens em laboratório. Algumas oficinas durante o movimento FotoBahia foram realizadas com essa finalidade, a de capacitar os fotógrafos. Alguns dos membros já tinham essa experiência, pois trabalhavam em jornais, e esses que já tinham uma base eram os responsáveis por ensinar os demais.

Isso se dava da seguinte maneira: se grande parte do grupo sentisse necessidade de aprofundar seus conhecimentos ou aprender uma técnica nova, era feito o convite a

Revista Digital do LAV - Santa Maria - vol. 9, n. 1, p. 128 - 144. - jan./abr. $2016 \quad$ ISSN 1983 - 7348 http://dx.doi.org/10.5902/1983734821927 
alguma pessoa que dominasse o assunto para ministrar oficinas para os membros do coletivo. Não só aprender técnicas de laboratório, mas a própria linguagem fotográfica, a história da fotografia e suas técnicas. Eram promovidos encontros e trocas de informações e conhecimentos. Se a formação fotográfica era quase nenhuma naquela época, imagina-se que a publicação sobre fotografia também era escassa, não existia livros nem autorais nem técnicos sobre a fotografia. Esses livros que o coletivo utilizava em seus estudos vinham de fora, e tinham de ser traduzidos para que o grupo pudesse estudar e desenvolver o seu trabalho.

FotoBahia se atentava, também, às questões ligadas a políticas públicas e as lutas políticas dentro da categoria, como a busca pelo direito autoral, pelos créditos aos fotógrafos nas fotos publicadas em jornais, os quais na época não eram considerados. Essas lutas diferenciavam a atuação do coletivo daquela do fotoclubismo e mesmo da fotografia mais especificamente artística que houve na Bahia na década de 1960 (DAMASCENO-FATH, 2012; 2011). O engajamento do coletivo consistia nessa luta pelo reconhecimento profissional dos fotógrafos nas áreas em que eles atuavam, seja no fotojornalismo, seja em outros meios de circulação da fotografia artística e documental. FotoBahia se constituiu também como um espaço para reunir e mostrar os trabalhos produzidos por profissionais e amadores que atuassem na área, não havendo tema definido, nem seleção, segundo o jornal FotoBahia de 1981.

FotoBahia foi uma iniciativa preocupada com o reconhecimento dos fotógrafos e com a formação dos mesmos, e também interessada em tornar os desconhecidos em conhecidos e reconhecidos, dentro da fotografia. Várias questões foram colocadas, nesse sentido: por exemplo, como se comunicar com um fotógrafo do interior, naquela época, sem a facilidade de comunicação que temos hoje? Como conhecer seus trabalhos, sua realidade, suas ideias, seus desejos? FotoBahia criou uma forma de compartilhar conhecimentos distantes geograficamente, unindo unir interior e capital, com reuniões semanais. $O$ interesse dos fotógrafos, certamente, os uniu nesse movimento, os fez deslocar de suas áreas e atrair fotógrafos que não fosse apenas do Recôncavo Baiano, buscando conhecer novos lugares, interagir com outras pessoas e culturas.

Levando em conta o momento de ditadura militar ainda vivido no país, FotoBahia, segundo alguns de seus integrantes, tinha certo papel de resistência, pois as exposições realizadas não passavam por nenhuma censura prévia, diferentes daquelas que eram publicadas em jornais ou revistas. De acordo com Boris Kossoy, as imagens da mídia, ao construir a informação, são um dos sustentáculos da construção da memória e podem constituir instrumentos de manipulação política e ideológica. As imagens fotográficas, controladas e censuradas, prestam-se como "provas", tornam-se instrumentos de poder

Revista Digital do LAV - Santa Maria - vol. 9, n. 1, p. 128 - 144. - jan./abr. $2016 \quad$ ISSN 1983 - 7348 http://dx.doi.org/10.5902/1983734821927 
para aqueles que controlam a informação (KOSSOY, 2007, p. 103-127). Entretanto, com o exemplo das formas de exposição e circulação utilizadas por FotoBahia, surge a importante hipótese de que nem toda a produção fotográfica do período da ditadura particularmente próximo à reabertura democrática, já no final dos anos 1970 - estivesse necessariamente em função da reprodução ideológica ou sob controle estrito da censura.

Apesar de FotoBahia ter se engajado numa luta política, como era a do direito autoral, do crédito obrigatório e da reivindicação de salários melhores, as imagens produzidas não eram necessariamente de denúncia, pois a produção do Coletivo era aberta a diversos tipos de imagens, documentais e artísticas. Em certo momento de FotoBahia, houve quem começasse a questionar a fotografia apenas como denúncia social, sem estar dentro de um contexto mais elaborado estética e politicamente. Esse questionamento permite aproximar as proposições do Coletivo da ideia de um olhar engajado, proposta por Ana Maria Mauad, a qual não implica, necessariamente, em fazer denúncia apenas através do tipo de imagem que se produz, mas no posicionamento social do fotógrafo em relação aos temas que escolhe, à forma de abordá-los e à defesa dos espaços para produção e circulação fotográficas (MAUAD, 2008a). Por isso começamos este texto com a assertiva da famosa fotógrafa Berenice Abbott, formada na geração do fotojornalismo internacional e engajada nas questões daquele momento cabe uma investigação mais aprofundada que deslinde a apropriação dessas referências por parte dos fotógrafos baianos de que estamos tratando.

\section{A circulação e a exposição}

É importante pensar também em como era a divulgação dos catálogos de FotoBahia, quais eram as pessoas que tinham acesso - se eram somente fotógrafos, artistas em geral, ou pessoas do meio jornalístico. O catálogo tinha tiragem limitada e o próprio meio socioprofissional da maioria dos integrantes, ligados às classes médias, indicava um nicho particular de circulação. FotoBahia transformou o padrão de catálogo para o formato de jornal, a fim de tornar a divulgação do material produzido pelo coletivo num material fácil de se espalhar, algo mais panfletário para ser distribuído pelos corredores das universidades, teatros e demais espaços expositivos (Figura 1). Esses jornais, diferentemente dos catálogos, possuíam além de imagens, textos, isto é, talvez, uma forma de trabalhar a fotografia de forma mais explicativa. Não era somente a impressão das imagens, mas de textos acerca de tais imagens. Esses textos dos jornais produzidos

Revista Digital do LAV - Santa Maria - vol. 9, n. 1, p. 128 - 144. - jan./abr. 2016 ISSN 1983 - 7348 http://dx.doi.org/10.5902/1983734821927 
pelo coletivo falavam do que era o movimento FotoBahia, pelo que lutavam, o que produziam e com qual finalidade o faziam. Nesse novo meio de circulação, criado pelo coletivo, eram colocadas as questões políticas e técnicas, pois havia a tentativa de não realizar somente exposições, mas criar constantemente conteúdos abrangentes para divulgar o coletivo e seus trabalhos.

No que se refere aos espaços expositivos, naquela época, aqueles considerados nobres, "de arte", eram os museus e as galerias, e só na fase final do Coletivo foi realizada uma exposição nesse tipo de espaço, no caso, o Museu de Arte da Bahia. Sendo assim, é importante pensar a fotografia inserida nesse meio, o que a levou até lá, os motivos dessa mudança de espaço, a ampliação do espaço, que se deu na última exposição. Ou seja, nesse momento, com a fotografia sendo colocada em espaços consagrados, pode-se dizer que ela passa a ter um status de importância no Estado, como expressão pessoal, como arte. Em determinados momentos da história da arte, a fotografia, quando era considerada arte, era uma "arte menor" ou "mediana", segundo a análise de Pierre Bourdieu (1990), inferior às demais, considerando que o museu possui uma visão elitista e ligada a uma classe social dominante. Poucos museus aceitavam a fotografia, e FotoBahia conseguiu superar esse espaço, questionálo, conseguiu se colocar nesse lugar, embora este não fosse seu objetivo inicial.

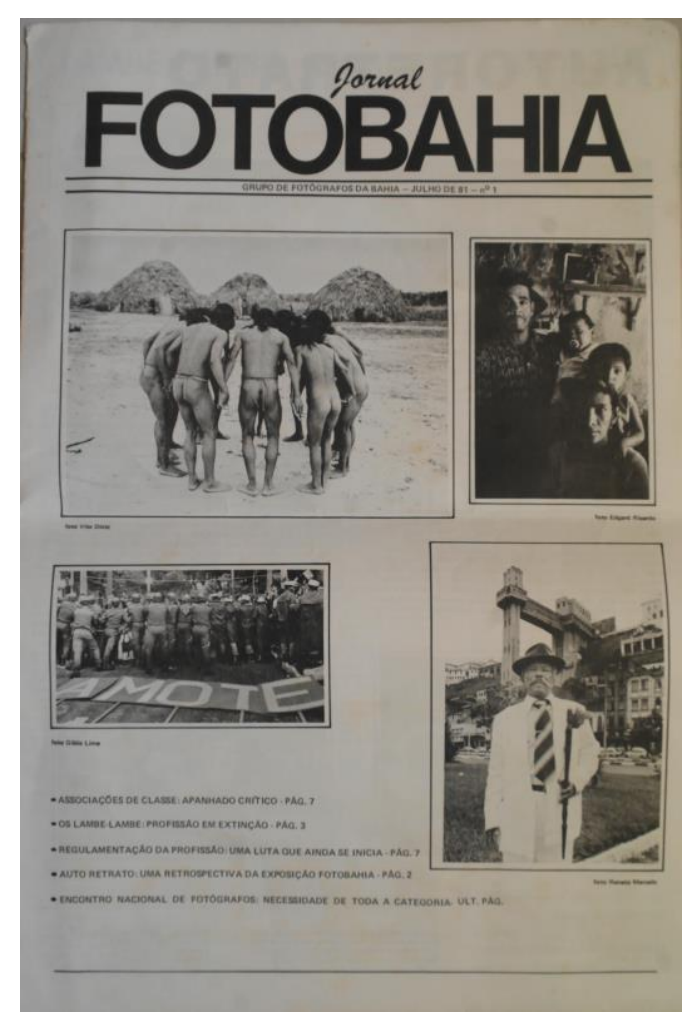

Figura 1: Jornal FotoBahia de 1981.

Revista Digital do LAV - Santa Maria - vol. 9, n. 1, p. 128 - 144. - jan./abr. 2016 ISSN $1983-7348$ 
Mas, como assinalamos, a produção de FotoBahia não pretendia ficar parada num museu, para ser apreciada num espaço de arte; quem possuísse os catálogos poderia ver e rever as imagens, revisitar as páginas quando bem entendesse. O coletivo se dispôs a questionar o que é arte, e qual seu espaço de circulação, qual o lugar da fotografia, como produzir e até o que produzir. A época era outra, os pensamentos e ideias eram outros, mas refletir sobre porque a fotografia era considerada uma "arte menor" ainda se faz necessário.

"Arte menor" é um termo utilizado para designar uma produção que, para aqueles que utilizam esse termo, não exigiu muito do artista, não o fez ficar horas trancado no seu atelier trabalhando naquela peça, por exemplo. Esse termo era utilizado para com a fotografia, e muitas vezes ainda é, pois se tem uma ideia de que é a produção da imagem fotográfica é puramente mecânica, o que não é. Naquele momento de FotoBahia, as dificuldades de trabalhar as técnicas eram muitas, desde a falta de equipamentos bons até a escassez de materiais para revelar e editar as fotografias. Pode-se imaginar quanto tempo era gasto para revelar uma foto, quanto tempo um fotógrafo ficava confinado num laboratório trabalhando numa imagem, buscando a granulação desejada, por exemplo. A "arte menor" foi um termo utilizado para inferiorizar a prática fotográfica, porém, é visível que tem lá as suas dificuldades para realizar esse tipo de trabalho da mesma forma que as artes manuais, como a pintura, o desenho, a gravura etc.

Com integrantes de formação e trajetória distinta, que produziam imagens com seus diferentes propósitos e olhares, a fotografia naquele momento de FotoBahia não só discutiu qual era o seu lugar, mas também o conceito de arte, e também ajudou na criação e na divulgação da fotografia, tendo promovido, ainda, novas interpretações sobre a cultura baiana, a partir de novas imagens.

\section{As formas e os temas de FotoBahia}

Um exercício metodológico proposto foi examinar as qualidades técnicas das fotografias, os ângulos escolhidos, a nitidez, os primeiro, segundo, terceiro planos, analisar o local e as pessoas retratadas, bem como os objetos e o tempo retratado e como isso influenciou no objeto final, a fotografia. Fizemos a leitura das imagens a partir de um breve estudo sobre o plano do conteúdo e o plano da expressão. Como propõe Mauad (2008b, p. 29-47), o plano do conteúdo é aquele que considera a relação dos elementos da fotografia com o contexto no qual se insere, remetendo-se ao corte

Revista Digital do LAV - Santa Maria - vol. 9, n. 1, p. 128 - 144. - jan./abr. 2016 ISSN 1983 - 7348 http://dx.doi.org/10.5902/1983734821927 
temático e temporal realizados. Analisar o conteúdo de uma imagem é "catalogar": agência produtora/ano, local retratado, pessoas retratadas, objetos retratados, atributo das pessoas, atributo da paisagem, tempo retratado (dia ou noite) e o número da foto.

O plano da expressão pressupõe a compreensão das opções técnicas e estéticas, as quais, por sua vez, envolvem um aprendizado historicamente determinado que é pleno de sentido social. Para analisar a expressão da imagem é preciso saber: a agência produtora/ano, tamanho da foto (para analisar as condições técnicas de circulação), formato da foto e suporte (relação com o texto escrito), tipo de foto (retrato, paisagem, foto de interiores), sentido da foto (horizontal ou vertical), direção da foto (direita, esquerda, centro), distribuição de planos, objeto central (analisar o arranjo e o equilíbrio da imagem), nitidez (foco, impressão visual, definição de linhas, iluminação), produtor (amador ou profissional), número da foto. Nesse ponto, consideramos o tamanho da foto e o suporte variáveis, dado que as imagens de FotoBahia circulavam tanto nas exposições quanto nos catálogos. Ressalto que mencionar se o produtor era amador ou profissional não é importante, pois considerando que FotoBahia era um coletivo que reunira fotógrafos, todos os membros eram designados assim, e não separados por amadores e profissionais, estavam todos ali para aprender e praticar a fotografia.

Para cada imagem dos catálogos de 1979 e 1980, foram escritos pequenos textos analíticos, de acordo com os critérios citados acima. Com esse exercício, foi possível notar as diferenças e semelhanças nas fotografias, e analisar a ordem das imagens, se os fotógrafos publicavam mais de uma foto por catálogo ou não, se as fotos tinham um padrão no tema ou não. Foram cerca de 74 fotos analisadas do catálogo de 1979, e no catálogo de 1980 foram 44 fotografias. Pudemos observar que no primeiro catálogo estudado havia mais imagens, obviamente, e mais fotógrafos, pois nenhum se repetia, além de estarem em ordem alfabética. No catálogo seguinte, o número de imagens diminuiu, bem como o de autores, que também não se repetiam, e não se encontram em ordem alfabética. Isso é próprio à dinâmica de trabalho de coletivos, enquanto grupos que sofrem mudanças constantes, com entradas e saídas de membros, ou seja, é algo que está em movimento.

Sobre as temáticas frequentes, nos catálogos de 1979 e 1980, parece que, apesar do slogan de um dos catálogos ser "revelar as realidades de um povo", os fotógrafos não estereotipavam aquilo que fotografavam, considerando-se o que já se entendia como sendo "típico" desse Estado. O tema principal era a Bahia, a partir de um "olhar nativo" um tipo de olhar que viria de dentro do próprio Estado, e não do exterior, como havia sido, por exemplo, o de Pierre Verger. Esse novo olhar proposto viria dos fotógrafos que residissem há bastante tempo na Bahia ou que dali fossem naturais - abrangendo não

Revista Digital do LAV - Santa Maria - vol. 9, n. 1, p. 128 - 144. - jan./abr. 2016 ISSN 1983 - 7348 http://dx.doi.org/10.5902/1983734821927 
apenas as culturas negras, as religiões de matriz africana, como o Candomblé, as festas populares, enquanto imagens que, naquela época, já constituíam estereótipos sobre a cultura baiana, fixados inclusive por grandes nomes da fotografia baiana do passado, como Voltaire Fraga (ALVES et. alli, 2006). Não que essas imagens não apareçam, nos catálogos estudados, porém, há diversas imagens que fogem a isso. As fotografias vão além do Recôncavo, vão para o interior do Estado, como já mencionado anteriormente, por conta dos fotógrafos vindos de outras regiões, que é o que FotoBahia pretendia: mostrar os recortes fotográficos que cada fotógrafo dava à Bahia, mostrar outras realidades. De certa forma, FotoBahia colocava a questão de pensar a fotografia enquanto linguagem, e não só como registro ou ferramenta para a História ou a Antropologia, e até mesmo enquanto arte, além de questionar, também, os espaços consagrados de arte, como indicamos.

Abaixo, duas fotografias nos mostram essa tentativa de fuga dos estereótipos baianos, e mais duas para mostrar que elas conviviam com imagens do "típico", uma ideia construída em momentos decisivos da formação do imaginário brasileiro sobre a Bahia.

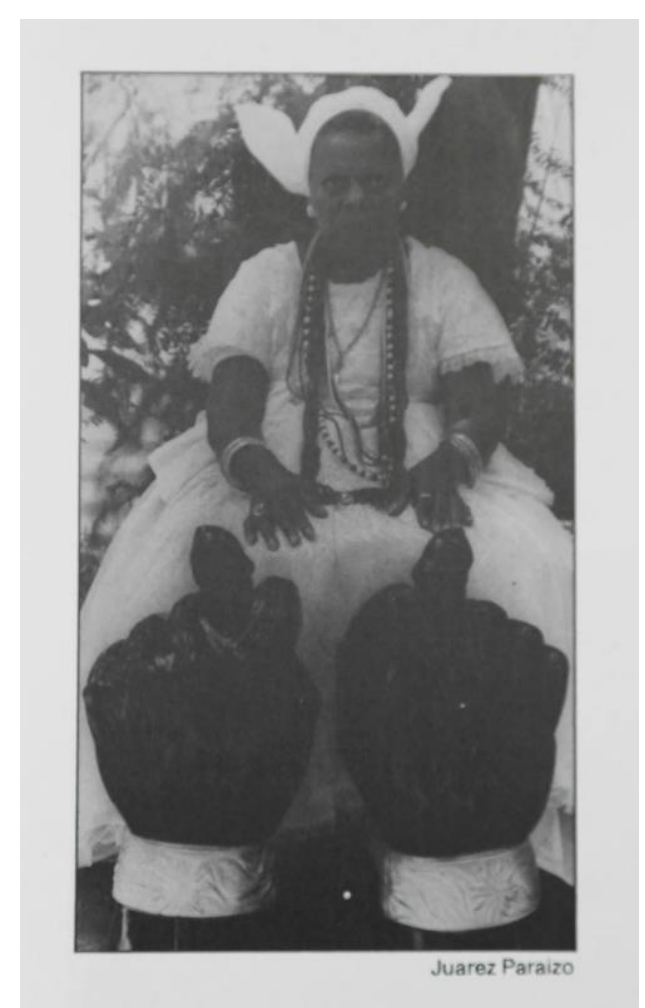

Figura 2: Foto de Juarez Paraízo, Catálogo FotoBahia de 1979.

Este retrato é do fotógrafo Juarez Paraízo, que está no catálogo de 1979 (Figura 
2). Uma imagem centralizada de uma mãe de santo, muito provavelmente no terreiro, em frente a duas figas com dedos que parecem falos, símbolo da fertilidade e de comunicação, no Candomblé. Além de observar os elementos que compõem a fotografia (as figas, as vestimentas as plantas ao fundo), é importante notar também os planos utilizados, o foco, a nitidez da imagem, as luzes e sombras. Com esse retrato pode-se ter a visão da Bahia voltada para o Recôncavo, suas culturas e religiões negras. A imagem dialoga com a produção da fotografia antropológica, já consagrada naquele momento (ANDRADE, 2002).

FotoBahia parece buscar ir além, podemos encontrar, até dentro de um mesmo catálogo, imagens que fogem disso. Como por exemplo a fotografia de Rosa Maria, também do catálogo de 1979. Nota-se aqui um tema diferente da fotografia de Juarez Paraízo, talvez tenha sido uma experimentação de um momento particular da fotógrafa, ou talvez ela tenha desejado sair do comum, daquela visão generalizada sobre a Bahia.

As fotografias de FotoBahia não estão separadas por gêneros ou temas, há uma variedade de imagens, como paisagens, retratos, fotos de interiores, pessoas negras, brancas, trabalhadores, músicos, crianças, adultos. Esta de Rosa Maria claramente se distingue da ideia formada sobre a Bahia, além de ter um teor erótico, que é poucas vezes encontrado nos catálogos estudados, também aparenta ter um viés artístico, uma experimentação (Figura 3). E analisando o ângulo, a forma deste retrato também é diferente da maioria, pois notando-se a barra clara na parte inferior da foto, dá para entender que é a parte de uma base onde a câmera foi posta para realizar este retrato, uma maneira diferente de fotografar.

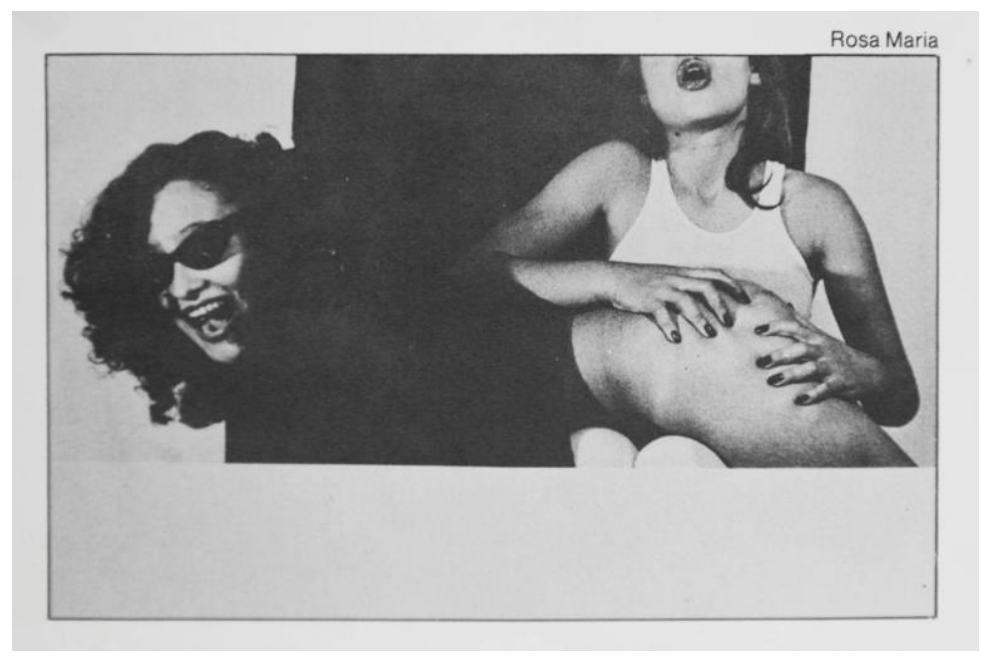

Figura 3: Foto de Rosa Maria, Catálogo FotoBahia de 1979.

Também é possível notar essas diferenças no catálogo de 1980. Esta paisagem é de

Revista Digital do LAV - Santa Maria - vol. 9, n. 1, p. 128 - 144. - jan./abr. 2016 ISSN 1983 - 7348 http://dx.doi.org/10.5902/1983734821927 
Luiz Fernando Pinto, registro de um porto com várias embarcações aportadas e pescadores circulando entre elas (Figura 4). É também uma imagem clichê sobre a Bahia, tanto do lugar registrado quanto das pessoas, a Bahia litorânea, portuária. Há uma confusão de linhas causada pela abundância de luz e sombra, é uma imagem com bastante informação, difícil de decifrar. O fotógrafo, talvez, tenha feito este registro com a finalidade de mostrar esse local tumultuado; paisagem feita de um local mais elevado, pois é visível a parte de dentro dos barcos e não suas laterais, como de costume. Apesar de ser uma fotografia de um tema recorrente, o modo como foi feita parece incomum, considerando a posição do fotógrafo, a luz formando linhas com as sombras, deixando a imagem conturbada.

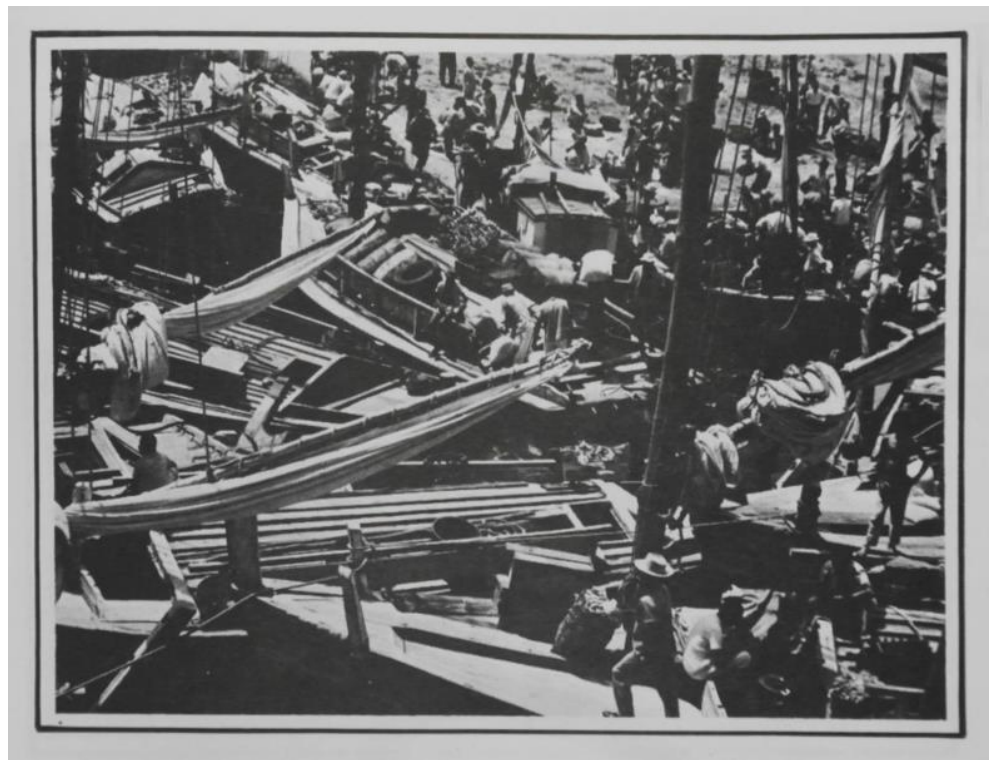

Figura 4: Foto de Luiz Fernando Pinto, Catálogo FotoBahia de 1980.

Na Figura 5, temos uma paisagem vertical do fotógrafo Aristides Baptista, também do catálogo de 80. Esta imagem além de se distanciar da Bahia comum, foi feita de um ângulo diferente também, de cima. É possível notar a sombra não só das crianças, o foco principal da imagem, mas a sombra do próprio fotógrafo na parte esquerda inferior. Provavelmente, esta imagem tenha sido programada para registrar, sob este ângulo, as sombras por completo, os objetos que seguram, o movimento que a garota faz com a mão direita, parecendo dar o livro à outra criança, observando sua sombra.

Em várias fotografias dos catálogos é possível notar também muitas imagens do sertão, de rios, fotografias de espaços interiores, como casas e igrejas. Como dissemos, FotoBahia procurou essa diversidade, trazendo fotógrafos do interior do Estado para que tivessem uma outra experiência com aquela região. Quanto às formas com que as

Revista Digital do LAV - Santa Maria - vol. 9, n. 1, p. 128 - 144. - jan./abr. $2016 \quad$ ISSN 1983 - 7348 http://dx.doi.org/10.5902/1983734821927 
fotografias foram publicadas nesses dois catálogos, vemos que as imagens do catálogo de 1979 possuem uma fina borda preta, enquanto as imagens do catálogo de 1980 possuem uma borda grossa branca e uma borda média preta, formando uma espécie de moldura. As fotografias vinham seguidas dos nomes de seus autores, no catálogo de 1979 o nome do fotógrafo era colocado perto da borda da foto - em cima para fotografias na horizontal ou em baixo para imagens na vertical -, e a fonte era pequena, considerando o tamanho da imagem. Já no catálogo de 1980, os nomes dos fotógrafos eram colocados em cima da foto (para paisagens e imagens na horizontal), ou ao lado na vertical (para as fotografias na vertical). Além dos nomes dos autores das imagens, não havia nada escrito, nem um texto sobre a fotografia.

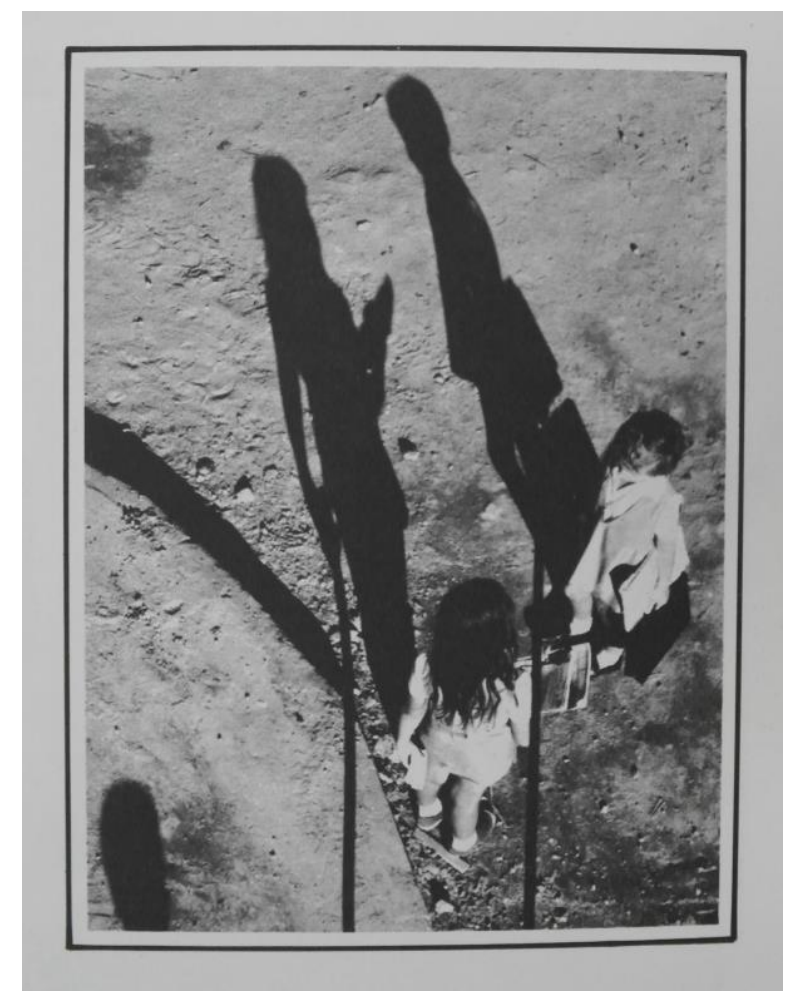

Figura 5: Foto de Arestides Baptista, Catálogo FotoBahia de 1980.

No que se refere à temática da denúncia social, sobre a qual comentamos, é interessante pensarmos na distinção entre as imagens de folclore ou denúncia, feitas em torno de determinados temas sociais. Lourdes Grobet indica que uma imagem torna-se folclórica quando um fotógrafo não se une às causas dos miseráveis, e suas fotografias não se aliam à luta contra a miséria. O fotógrafo escolhe o que irá registrar, no momento em que ele enquadra a câmera para realizar uma fotografia, ele seleciona o que vai dar a ver e o que deixará oculto. Para Grobet, a maneira mais honesta de fotografar seria produzir imagens com a maior consciência da situação e com clara intenção de denúncia,

Revista Digital do LAV - Santa Maria - vol. 9, n. 1, p. 128 - 144. - jan./abr. 2016 ISSN 1983 - 7348 http://dx.doi.org/10.5902/1983734821927 
não com a mera finalidade de chocar quem vê a imagem, mas de provocar uma reflexão (GROBET, 2006).

Nos catálogos de 1979 e 1980, há diversas fotografias que podem ser consideradas imagens de denúncia, contudo, analisamos aqui uma que chama bastante atenção. 0 retrato a seguir é do fotógrafo Josué Ribeiro, publicado no catálogo de 1979 (Figura 6). Nele, vemos uma criança em pé, que inclina-se para frente e parece estar chorando ou gritando, e por trás dessa criança está um amontoado do que parecem ser destroços de uma casa. Pode ser um registro para algum jornal, que foi trazido para a exposição e para o catálogo, um registro de denúncia sobre as condições do local retratado. 0 fotógrafo registrou um momento de desespero da criança, porém, como colocado por Grobet, ele pode somente ter aproveitado aquele instante para registrar uma imagem a fim de causar um forte impacto, um choque para quem a vê. Não podemos saber qual foi a ideia do fotógrafo ao fazer esse registro, tendo em vista que - como acontece frequentemente com as imagens - as fotos publicadas nos catálogos de FotoBahia se encontram suscetíveis a muitas leituras, não possuindo textos que as narrem.

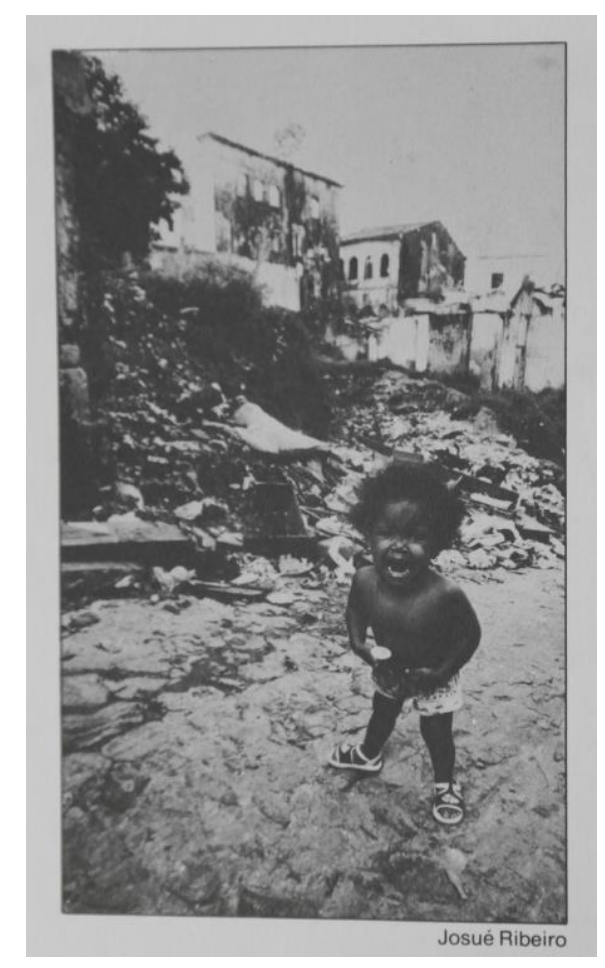

Figura 6: Foto de Josué Ribeiro, Catálogo FotoBahia de 1979.

Pela recorrência desse tipo de temas, FotoBahia poderia ser um compilado de 
fotografias engajadas, relacionadas ao fotojornalismo, sem abrir mão de sua dimensão expressiva. Neste sentido, os textos introdutórios dos catálogos de 1979 e 1980, por exemplo, são escritos por jornalistas, Mariluce de Souza Moura e Symona Gropper. As autoras contam sobre a trajetória da fotografia na Bahia, relembram um passado fotográfico remetendo não só à arte, mas ao fotojornalismo e ao circuito comercial de estúdios, que, frequentemente começava em Salvador e, só depois, adentrava o interior. Mariluce descreve que com o desenvolvimento do fotojornalismo, os fotógrafos puderam crescer profissionalmente nos jornais; depois vieram a publicidade e a fotografia que se definia como artística, que passaram a ser campos paralelos para o desenvolvimento de profissionais, e o fotojornalismo (MOURA, 1979).

Symona Gropper, por sua vez, escreve sobre a importância da fotografia, os porquês da fotografia, bem como as suas intenções. Defende a fotografia como transmissora de uma mensagem que é entendida por todos, seja intelectual, analfabeto, estrangeiro, e também coloca a fotografia num papel social: o de educar, além de ser um meio de comunicação social. FotoBahia, segundo esta jornalista, seria um movimento que se repete sem discriminar, abrangendo profissionais, amadores, artistas, professores. Symona Gropper destacava a diversidade de usos, o que levanta ainda mais questões sobre como era considerada a produção do Coletivo: por um lado, "[a fotografia] serve para tudo nesta Bahia. Mostra o trágico, como mostra o folclórico", fixa um momento de misticismo ou de alegria, revela a decadência e "vende" a Bahia para os turistas; mostra seus aspectos belos, antigos e precisos, sensuais e religiosos. Por outro lado, a fotografia se encarregaria de denunciar problemas de minorias que não têm quem fale por elas, este seria o trabalho do fotojornalista, que está próximo dos problemas sociais abordados diariamente nos jornais, e que por isso acaba se tornando sensível, sentindo a necessidade de realizar um trabalho que denuncie as sub-condições de vida de determinado povo (GROPPER, 1979).

Por fim, Symona Gropper diz que a fotografia imobiliza a cultura, a qual dilui-se com o tempo, no papel, num momento de sua manifestação viva, autêntica; deixa uma memória concreta da Bahia, palpável, de como foi aquele lugar, e não o será mais. É necessário salientar que a jornalista talvez vincule tão explicitamente as imagens de FotoBahia ao fotojornalismo por sua própria formação, sendo essa apenas uma das possíveis interpretações sobre as imagens de FotoBahia.

A produção de FotoBahia sofria, então, pelo menos, algumas leituras diferentes, inclusive por parte dos seus produtores e comentadores, à época, que oscilavam entre classificá-las como artísticas, de denúncia, antropológicas, históricas e até folclóricas. Aparentemente, cada fotógrafo escolheu publicar aquela imagem que the 
aprouvesse na época. Separar as imagens por campo específico, enfim, pode ser redutor para lidar com a abrangência do Coletivo e com a diversidade dos que o compunham. Se entendemos "coletivo" como uma junção de coisas, pessoas, ideias, processos, é preciso também compreender as variedades das fotografias expostas e divulgadas. Observando cuidadosamente as imagens, e até mesmo pesquisando os produtores, quem eram, o que faziam, com o que trabalhavam, é possível se aproximar minimamente de seu universo de significação - este, então, é um veio ainda a ser explorado pelas pesquisas.

Analisando as imagens, é interessante pensar, ainda, no porquê da escolha em preto e branco, já que na época estava em desenvolvimento a fotografia colorida, qual teria sido a proposta e qual a finalidade. Podemos pensar que a escolha pela fotografia em preto e branco, considerando que naquela época as condições eram outras, os laboratórios fotográficos poderiam não ser tão desenvolvidos ou não tão acessíveis. Ou pode-se pensar também que, como o coletivo organizava suas próprias oficinas com a finalidade de aprender determinadas técnicas, os fotógrafos teriam passado por esse processo de trabalhar com um equipamento já tradicional no universo da fotografia, de experimentar luz e sombra, granulação da imagem, e a opção do preto e branco tenha sido a mais indicada para desenvolver técnicas específicas.

Uma outra hipótese pode ser a de que, como os fotógrafos não eram tão reconhecidos profissionalmente, a forma mais barata e que abrangesse todo o grupo seria trabalhar com o preto e branco, já que a imagem colorida era uma novidade que estava se afirmando nos usos mais amplos e que poderia aumentar os custos. Ser fotógrafo era, além de trabalhoso, relativamente caro, como visto numa tabela publicada no Jornal FotoBahia de 1981, a qual divulgava os preços dos materiais fotográficos, com a porcentagem de $706 \%$ do aumento em 18 meses, a partir de uma pesquisa feita por Artur Viana, um dos fotógrafos do Coletivo.

\section{Considerações Finais: FotoBahia, abertura de um lugar para as imagens}

Olhar demoradamente uma fotografia requer não só paciência, mas um olho treinado para enxergar as miudezas da foto, os pequenos detalhes que podem fazer uma enorme diferença na leitura da mesma. Symona Gropper, no texto introdutório do catálogo de FotoBahia de 1980, repete o clichê segundo o qual "uma boa foto fala melhor do que mil palavras", mas podemos dizer que a fotografia fala também através das palavras e formas de circulação que a mediam, como também por meio dos olhos do

Revista Digital do LAV - Santa Maria - vol. 9, n. 1, p. 128 - 144. - jan./abr. $2016 \quad$ ISSN 1983 - 7348 http://dx.doi.org/10.5902/1983734821927 
observador, já que é ele que vai tirar suas próprias conclusões acerca daquela imagem. Então, uma imagem fala diferentemente do que palavras, dependendo do espectador, se ele consegue lê-la e interpretá-la ou não.

Como já dito antes, a fotografia é passível de interpretações variadas, o fotógrafo pode interpretar de uma maneira distinta da que o público interpreta. Essas diferenças ressignificarão as imagens a cada momento em que elas forem encontradas. O contexto mudará, e ela será analisada de forma diferente, o que representa, o que significa, o que retrata. O fotógrafo é o primeiro sujeito que interpreta aquilo que retrata, ou bem antes, interpretando o momento que está a retratar. Em seguida, vêm o público, os observadores, que interpretarão aquela imagem feita de acordo com o que entender, sentirem, com toda a sua bagagem visual, com toda sua experiência e vivência.

FotoBahia foi um movimento importante, não só para Estado em questão mas para todo o país, pois ajudou a desenvolver um olhar diferente acerca da fotografia, incentivou os fotógrafos a continuarem produzindo, ajudou a problematizar o lugar da fotografia no meio artístico. FotoBahia criou meios de transmitir informações sobre a fotografia (o seminário, as oficinas, os catálogos, os jornais), e foi responsável por mediar essas informações, por analisar e selecionar o que transmitiria para o público interessado. O coletivo foi uma forma de resistência dos fotógrafos naquele momento, durante oito anos. Foi uma experiência que possibilitou aos fotógrafos se expandirem na sua profissão, os ajudou a se desenvolverem após o encerramento de suas atividades no FotoBahia, já que durante todo o período do movimento eles foram incentivados dentro da sua área de atuação (fotojornalismo, fotografia artística, publicidade).

A importância de FotoBahia, além de trabalhar e desenvolver a fotografia, é também a valorização que a linguagem fotográfica deu à cultura do Estado. Hoje, graças a iniciativa FotoBahia, podemos estudar uma visão da produção cultural da Bahia bem rica e realizada pelos fotógrafos baianos, naquela época, e os que ainda estão a produzir atualmente. FotoBahia foi isso, um incentivo para que os fotógrafos criassem seus trabalhos e projetos autorais, e também que continuassem a produzir. Sinal disso é que boa parte dos integrantes do coletivo trabalham até hoje com a fotografia, e outros com produções ligadas indiretamente à fotografia.

\section{Referências}

ABBOTTT, Berenice. La fotografia en la encrucijada. In: FONTCUBERTA, Joan (org.). Estética fotográfica. Barcelona: Gustavo Gili, 2003.

Revista Digital do LAV - Santa Maria - vol. 9, n. 1, p. 128 - 144. - jan./abr. 2016 ISSN 1983 - 7348 http://dx.doi.org/10.5902/1983734821927 
ALVES, Aristides; FREITAS, Antonio Fernando Guerreiro de; SAMPAIO, Maria Guimarães; FERNANDES JUNIOR, Rubens; FALCON, Gustavo. A Fotografia na Bahia (1839-2006). Salvador: Asa Foto, 2006.

ANDRADE, Rosane de. Fotografia e Antropologia. Olhares fora-dentro. São Paulo: Estação Liberdade; EDUC, 2002.

BOURDIEU, Pierre. The social definition of photography. In. . Photography. A middle-brow art. Stanford: Stanford University Press, 1990.

COELHO, Maria Beatriz. Imagens da Nação: brasileiros na fotodocumentação de 1940 até o final do século XX. Belo Horizonte: UFMG; São Paulo: Imprensa Oficial do Estado de São Paulo; EDUSP, 2012.

DAMASCENO-FATH, Telma C. Memória do Fotoclubismo na Bahia. Discursos Fotográficos (Online), v. 8, p. 175-195, 2012.

. A Fotografia na II Bienal Nacional de Artes Plásticas da Bahia. Revista de Arte Ohun. Salvador, v. 5, p. 54-64, 2011.

FOTOBAHIA 79. Salvador: s; e, 1979.

FOTOBAHIA 80. Salvador: s; e, 1980.

GROBET, Lourdes. Imágenes de miseria: folclor o denuncia. In: MARZO, Jorge Luis (ed.) Fotografía y activismo. Textos y prácticas (1979-2000). Barcelona: Gustavo Gili, 2006.

GROPPER, Symona. Um retrato sem retoque. In: A fotografia na Bahia (apesar das perdas, um retrato nítido de mais de um século). In: FOTOBAHIA 79. Salvador: [s; e], 1979.

GRUPO DE FOTÓGRAFOS DA BAHIA. Jornal FotoBahia. Salvador: s; e. n. 01.

KRAUSS, Rosalind. Os espaços discursivos da fotografia. In: - O fotográfico. Barcelona: Gustavo Gili, 2010.

KOSSOY, Boris. Mídias: imagens, ideologia, memória. In: fotografia. Cotia: Ateliê Editorial, 2007.

MAUAD, Ana Maria. O olhar engajado: fotografias contemporâneas e as dimensões políticas da cultura visual. ArtCultura. Uberlândia, v. 10, n. 16, p. 33-50, jan.-jun. 2008 [2008a]. 2008 [2008b].

Poses e flagrantes. Ensaios sobre história e fotografias. Rio de Janeiro: EDUFF,

MOURA, Mariluce de Souza. A fotografia na Bahia (apesar das perdas, um retrato nítido de mais de um século). In: FOTOBAHIA 79. Salvador: [s; e], 1979. 